\title{
Operation Constraints and Methodology for Stability Preservation in Power Systems with High Penetration of Non-Synchronous Generation
}

\author{
I. Taczi ${ }^{1}$, I. Vokony ${ }^{1}$ \\ ${ }^{1}$ Department of Electric Power Engineering \\ Budapest University of Technology and Economics \\ Egry Jozsef str. 18. -1111 Budapest (Hungary) \\ Phone/Fax number: +36305166473, e-mail: taczi93@gmail.com, vokony.istvan@vet.bme.hu
}

\begin{abstract}
Nowadays, significant changes in the electricity generation mix raise questions about the secure operation of power systems. Most of the newly installed generation capacity is being connected to the grid via power electronic converters, thus can be seen as a non-synchronous generation. The theory of power system operation and control relies heavily on the characteristics of synchronous machines and conventional network structure. Therefore, the effective integration process of the new technologies must include the composition of new physical models for converter dominated large power systems as well as innovative solutions to ensure the secure operation in the future. The focus of this paper is a holistic analysis of the reducing power system inertia to frame up new constraints for system operators through simulation studies on the Institute of Electrical and Electronics Engineers standard 118 bus test system. The different system states and scenarios offer a comparison opportunity between stability preservation possibilities. Minimum inertia constraint calculation methodologies and various objective functions are being discussed. The utilization and effects of synthetic inertia from non-synchronous generators and energy storage systems is also considered to quantify the exact effects.
\end{abstract}

\section{Key words}

Power System Stability, Power System Inertia, Synthetic Inertia, Renewable Energy Sources, Non-Synchronous Generation

\section{Introduction}

Renewable energy sources have clearly outgrown the alternative label in the past years. According to the International Energy Agency, almost two thirds of the newly installed generation capacity came from renewables in 2016, thanks in part to a 50\% overall growth in solar energy. [1] Incentives from policy makers made impressive emission reduction goals feasible, but the effective integration of new technologies still has lots of open questions. [2] Wind and solar generation behave quite differently from the conventional synchronous generators. Apart from the intermittent nature caused by the variation of wind speed and irradiation, most of these sources do not contribute to the power system inertia inherently due to the electrical decoupling of power converters. [3] The inertial frequency response of synchronous machines is taking place directly after any electric power imbalance in the system as the stored kinetic energy in the rotating mass of those machines limits the rate of change of frequency (ROCOF). [4] The kinetic energy extraction (under frequency events, when the machine slows down) or absorption (over frequency events when the machine accelerates) ensures system stability as a physical response until controlled reserves could be activated. Therefore, the high penetration of non-synchronous generation might cause frequency instability issues through the reduction of rotating mass. Due to the inertia reduction, the ROCOF of the power system may be high enough to activate the load-shedding processes even in case of a small power imbalance between generation and consumption. The European Network for Transmission System Operators - Electricity (ENTSO-E) discussed this issue in detail in recent publications. [5-8] The growing share of intermittent sources also decrease the frequency containment (FCR), frequency restoration (FRR) and replacement reserves (RR) in the system which must be taken in to account in the operation planning phase. To overcome the issues, these new generators should provide frequency control services for the system. Energy storage devices also could offer viable reserve capacity at the entire value chain of system operation and control. [2]

The focus of this paper is to examine stability preservation methods with simulation studies performed in the DigSilent Power Factory 15.1 Software. Minimum synchronous generation constraints [9] being tested and further developed with the addition of synthetic inertia control on a standard Institute of Electrical and Electronics Engineers (IEEE) 118 Bus system. [10] The introduced methodology provides useful principles for the composition of stability preservation strategies of power systems with high penetration of non-synchronous generation. However, a complete stability reserve planning will require further studies in the future. 


\section{Methodology}

The robustness of a power system is measured by the ability of operating in a state of equilibrium under normal and perturbed conditions. The discipline of power system stability deals with the study of the system behaviour under extreme conditions, such as short circuits, generator outages or sudden changes in load. The system is stable if the interconnected generators remain in synchronism. In case of a severe disturbance, the dynamic motion of the synchronous generators is determined by the swing equation. [11] Frequency stability focuses on overall response of the system as evidenced by its mean frequency, rather than the relative motion of machines. Therefore, in a single bus frequency model, the swing equation can be expanded to a whole system. In this case the active imbalance could be calculated [9]:

$$
\Delta P=\frac{d}{d t} \cdot W_{k i n, s y s}+D_{s y s} \Delta f
$$

Where $\Delta \mathrm{P}(\mathrm{MW})$ is the power imbalance, $\mathrm{W}_{\text {kin,sys }}$ (in MWs) is the kinetic energy of the system, $\mathrm{D}_{\text {sys }}(\mathrm{MW} / \mathrm{Hz})$ is the damping coefficient and $\Delta \mathrm{f}(\mathrm{Hz})$ is the change of frequency. The first term is the inertial response of the system (in this form both generation and load), the second is a damping effect of the elements. The damping effects depend on frequency, voltage and time and it should be separated from the inertia analysis (but in most cases, the effects could not be neglected). Equation 2. describes the kinetic energy - ROCOF correlation [9]:

$$
\frac{d}{d t} \cdot W_{k i n, s y s} \approx \frac{2 W_{k i n, s y s}\left(f=f_{0}\right)}{f_{0}} \frac{d}{d t} \Delta f
$$

Where $\mathrm{f}_{0}(\mathrm{~Hz})$ is the nominal system frequency. It means that the kinetic energy changes proportionally to the frequency gradient. Due to the difficulty of accurately estimating the load's inertia, the system inertia is considered equal to the synchronous generation inertia in most of the studies. From the operator viewpoint this could be seen as a safety factor in a minimum inertia requirement. With this neglection, the system's kinetic energy in steady state operation could be calculated as in equation 3. [9]:

$$
W_{k i n, s y s}\left(f=f_{0}\right)=\sum_{i=1}^{N} H_{i} S_{i}
$$

The system contains $\mathrm{N}$ synchronous generators, $\mathrm{H}_{\mathrm{i}}$ is the inertia constant (s) of a single machine and $S_{i}$ is the apparent power (MVA) of it. If accurate information about the load inertia constants is available, it could be added to this summarization the same as the generation. This paper focuses on the ROCOF and frequency nadir parameters to evaluate frequency stability of the system, however stability is a complex problem and other aspects have to be considered in the composition of an operating solution. The complete stability preservation mechanism should include different modelling methods for each scenario, such as voltage and rotor angle stability, overloading, congestions and increasing variability due to the intermittent generation.

\section{A. Estimation of system inertia}

From equation 3., the kinetic energy of a system could be calculated for steady state operation if each parameter of the synchronous generators is available. Based on the swing equation, inertia could be estimated online and offline with analysis of the frequency curve during the disturbance. Several approaches exists to calculate the inertia of the system from measurement data as well as to monitor the relevant parameters online. [12-14] [7] Several transmission system operators run pilot projects to test different methods and provide feedback from practical experience. If such system is implemented, it could provide useful data and more flexible operation, thus can improve security of supply while being cost effective.

\section{B. Operation constraints}

In order to keep the ROCOF values under a predefined limit, constraints could be defined on the minimum available kinetic energy (system inertia). The time invariant constraint ensures that the ROCOF magnitude does not exceed the predefined value even if the most severe single fault, which can be described with the active power imbalance $\mathrm{P}_{\max }(\mathrm{MW})$. This could be a generator, a load, an export/import point depending on the actual grid topology. This is a static approach but more applicable. [9]

$$
W_{\text {kin,sys }}\left(f=f_{0}\right) \geq \frac{f_{0} P_{\max }}{2\left|\frac{d}{d t} \Delta f\right|_{\max }}
$$

The second constraint offers a more dynamic approach: instead of the time-invariant largest single equipment, $\mathrm{P}_{\text {max,act }}$ represents an actual largest element in the examined system state of the time step. [9]

$$
W_{k i n, s y s}\left(f=f_{0}\right) \geq \frac{f_{0} P_{\max , a c t}}{2\left|\frac{d}{d t} \Delta f\right|_{\max }}
$$

The increasing variability should also be considered in the constraints. According to ENTSO-E, future systems may face up to $40 \%$ imbalances and ROCOF up to 2 $\mathrm{Hz} / \mathrm{s}$. Hence the simulation scenarios also include load step changes to evaluate the short-term effects of variability. [8]

\section{Synthetic inertia provision}

Synthetic (or artificial, augmented, emulated, virtual) inertia is a control function which implements that nonsynchronous elements behaves similarly to the synchronous machines during frequency excursions, with the emulation of the hidden kinetic energy extraction or absorption effects. The utilization of the power converters for synthetic inertia services enhances the power system stability. It has to be activated autonomously with a very rapid response time (in the range of 50-100 ms). It is provided by non-synchronous generators (such as doubly-fed induction generator and full converter type wind turbines or solar panels), energy 
storage systems with power electronics, high voltage direct current (HVDC) converters or any other capable equipment. [15-27]

Figure 1. depicts the applied synthetic inertia controller topology. The grid frequency is measured with phaselocked-loops (PLLs). ROCOF is being composed with a differentiator and filtered properly to avoid unnecessary activations. The deadband block could provide selectivity functions and ensures the operational safety of the device (e.g. avoiding mechanical stresses of wind turbines [25]). The emulated inertia constant can be tuned properly, and also the controller can handle any kind of technology (energy storage, solar panels, wind turbines, HVDC etc.) with an active power setpoint possibility. The delayer/limiter block offers settings for operators to provide technology-based dynamics for the analysis, therefore the models could be validated with measurements. [17]

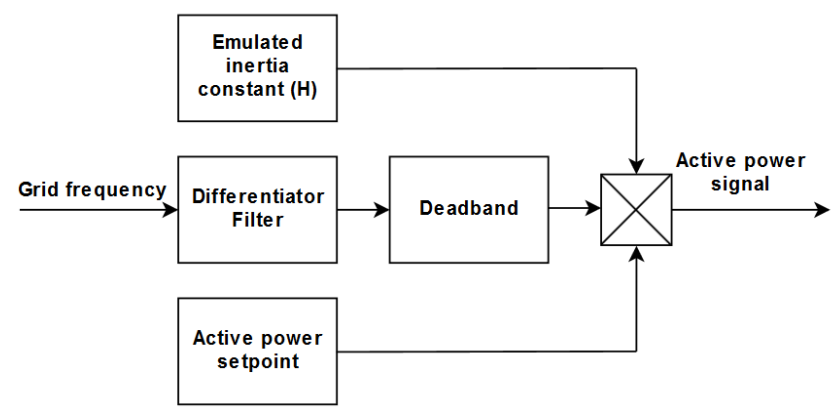

Fig. 1. Synthetic inertia controller overview [17]

In this study the controller emulates a $\mathrm{H}=10 \mathrm{~s}$ inertia constant with a group of 2,5 MW wind turbines (4 wind farms with 450 or $500 \mathrm{MW}$ aggregate power, as described briefly in section $3 / \mathrm{b}$.), the maximum inertial response power output is $0.1 \mathrm{p} . \mathrm{u}$, and a gradient limit is 1 p.u./s to provide a technically feasible simulation. No additional selectivity is provided. [17] [25]

The application of synthetic inertia can enhance frequency stability if utilized properly. Thus, the controlling is observable with the stability evaluation methods described as well as the activations have effects on the operation constraints. The purpose of this concept is to calculate and evaluate the effects of synthetic inertia with the extension of previously proposed methods on a well-known and standard power system model and offer a more flexible stability enhancement concept which confirms that nonsynchronous generators can offer highly valuable grid supporting functions.

\section{Simulation studies}

Evaluation of the stability preservation methods mostly carried out with dynamic network simulation software and tools. In this research, the DigSilent Power Factory 15.1 symmetrical steady-state stability analysis (RMS module) functions were used to analyse the electromechanical transients and emulated inertia effects. Generators, network topology and parameters are the same as the standard open access system in the base case. [10] The different level of non-synchronous penetration is implemented with the substitution of the standard system's conventional generators to type 4 full scale converter wind turbines. In the case of energy storage systems parameter sets describe a battery storage system, therefore it is also a power converter-based device. Disturbances are caused by load ramps and generator outages. All the simulations lasted 5 seconds, the disturbance occurred at $2 \mathrm{~s}$. No FCR or FRR effects were examined.

\section{A. The IEEE 118-bus system}

Figure 2. depicts the standard system model topology of the IEEE 118 bus system. It is the portion of Midwest Interconnected System from 1962, and consists of 118 buses, 186 transmission lines, 54 connected machines with a total installed capacity of 7.220 MW and a system could be divided to three regions. 19 synchronous generators provide active power to the system while other 20 is operating as a synchronous condenser and only provide reactive power to the system. Other 15 synchronous machines are motors in the model. The total system load is $3668 \mathrm{MW}$ and1438 MVAR, the nominal frequency is $50 \mathrm{~Hz}$. [10]

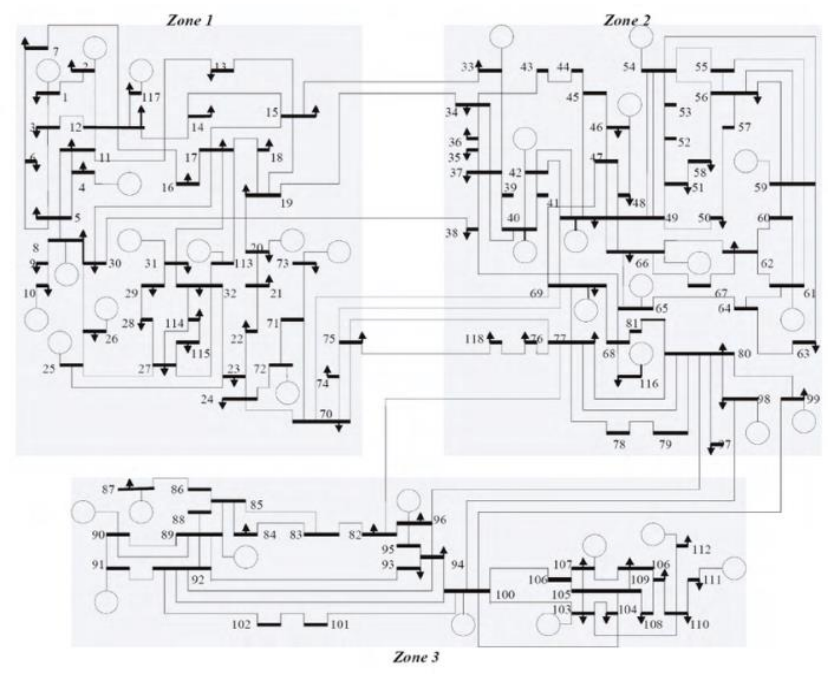

Fig. 2. Topology overview of the IEEE 118-bus system [10]

The loads were modelled as constant impedance type in this model, thus have a damping effect on frequency and voltage excursions. The inertia of the condensers and motors are also included in the kinetic energy calculations.

\section{B. Scenarios and results}

Two different disturbances cause the transient state of the system in the following simulation studies:

- $\quad$ step increment of load (5-25\% of the total system load in 5\% steps)

- the outage of the largest single element, a synchronous generator (a 835 MVA generator with the actual active power of $607 \mathrm{MW}$, unit number 89)

The share of non-synchronous generation is implemented by substituting synchronous generators with wind farms (consists of the same full converter type wind turbines 
equipped with the synthetic inertia activation possibility) with similar power output on different points of the system. Five different non-synchronous generation levels were examined, Table I. summarizes the parameters for each case.

Table I. - Non-synchronous generation implementation in the modelling, simulation cases

\begin{tabular}{|l|c|c|c|c|c|}
\hline & Base & Case 1. & Case 2. & Case 3. & Case 4. \\
\hline $\begin{array}{l}\text { Share of non- } \\
\text { synchronous } \\
\text { generation (\%) }\end{array}$ & 0 & 12.27 & 25.9 & 39.53 & 51.8 \\
\hline $\begin{array}{l}\text { Aggregated } \\
\text { wind farm } \\
\text { output (MW) }\end{array}$ & 0 & 450 & 950 & 1450 & 1900 \\
\hline $\begin{array}{l}\text { Generator } \\
\text { substituted } \\
\text { (unit no.) }\end{array}$ & $\mathrm{X}$ & 10 & 80 & 69 & 66 \\
\hline $\begin{array}{l}\text { Remaining } \\
\text { kinetic energy } \\
\text { (GWs) }\end{array}$ & 24.12 & 22.75 & 21.38 & 20.01 & 18.67 \\
\hline
\end{tabular}

\section{Quantification of the inertia reduction effects}

Figure 3. summarizes the ROCOF values measured in the simulation studies. This variable was defined as the system frequency derivative instantly after the disturbance. The different level of non-synchronous generation clearly affects the values, as in extreme conditions roughly $12,3 \%$ of non-synchronous generation growth leads to $10 \%$ ROCOF change (Case 3 - Case 4, 25\% load increment). The exact ROCOF constraint should be chosen in a way that every network element (generator, load, transmission and distribution element, protection device etc.) can operate but none of them would damage because of the power system parameter changes. The inertia reduction of the generation side also applies for the consumers, as power electronics offer more efficient and cost-effective operation. This means that the share of decoupled devices, and constant (the active and reactive power of the load is independent from the system frequency and voltage) power loads are getting more and more common. In case of an insecure parameter change, these devices disconnect from the grid as a protection function which could lead to more severe grid faults.

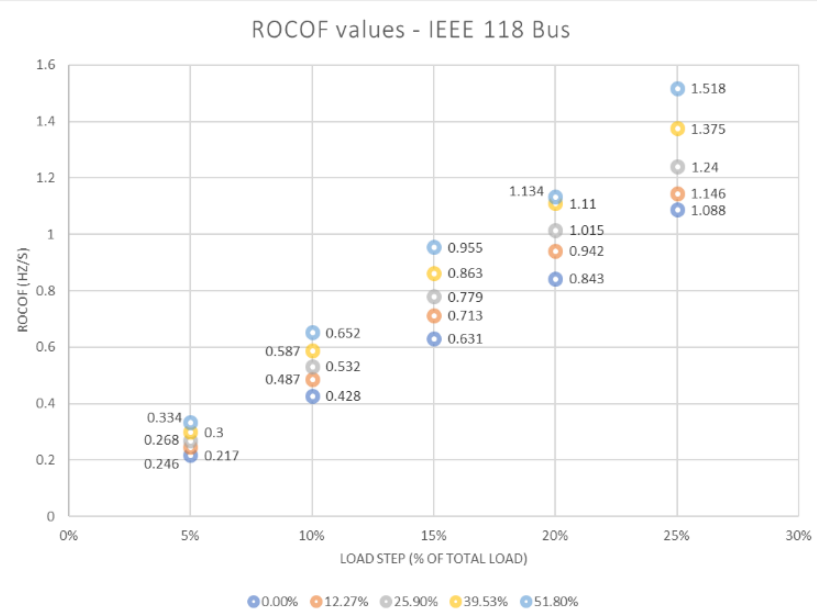

Fig. 3. Simulated ROCOF values with different power imbalances and non-synchronous generation level
With the knowledge of actual grid codes, regulations and consumer preferences the ROCOF constraints could be set based on these results for the system.

\section{Synthetic inertia activation}

If the ROCOF constraint could not be met with the actual generation mix and grid circumstances, a possible way to enhance stability is to activate synthetic inertia functions in non-synchronous generators. In Case 1, the $450 \mathrm{MW}$ wind farm (consists of 225 pcs. of full converter wind turbines, each with $2 \mathrm{MW}$ output power) provide $10 \%$ synthetic inertia controlling capability. The activation of emulated inertial response is much faster than conventional FCR, thus can be seen as the new first level of grid level frequency control. Figure 4. shows a possible output for a measured frequency value.

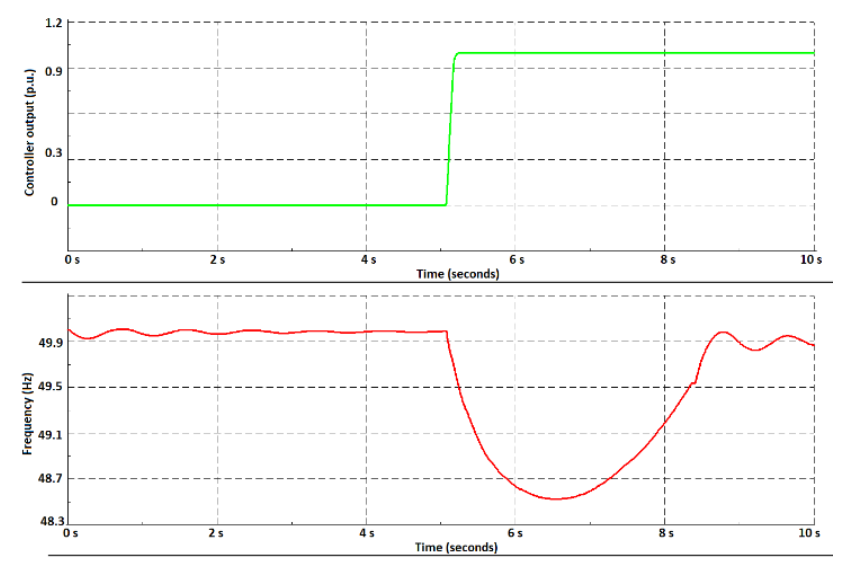

Fig. 4. Synthetic inertia controller output signal

Table III. summarizes the effects of synthetic inertia provision in Case 1. Both the frequency nadir and the ROCOF values were improved: the frequency absolute value stayed closer to the nominal value, the nadir was higher. Also, the ROCOF was limited as a lower value in every case. Compared to the Base case (Table II.), when only synchronous generators provided the power, the ROCOF values are slightly higher and the frequency nadir values are slightly lower. This means that the synthetic inertia control could not provide the same effect as the lost kinetic energy (1.368 GWs difference between Base case and Case 1.) but significantly improve the frequency stability during the disturbances. The effects can be quantified and included in the operation constraints to ensure effective, secure and reliable operation. The exact number (artificial kinetic energy) which describes the emulated inertia and can be included equation 4-5. should be examined further in future research.

Table II. - Base case frequency nadir and ROCOF values

\begin{tabular}{|c|c|c|c|c|c|}
\hline \begin{tabular}{|l} 
Kinetic energy (GWs) \\
\end{tabular} & 24.119 & & & & \\
\hline Non-synchronous penetration (\%) & $0.00 \%$ & & & & \\
\hline Synthetic inertia & None & & & & \\
\hline Load increase (\%) & $5 \%$ & $10 \%$ & $15 \%$ & $20 \%$ & $25 \%$ \\
\hline Frequency nadir (Hz) & 49.92 & 49.76 & 49.54 & 49.29 & 49.04 \\
\hline ROCOF $(\mathrm{Hz} / \mathrm{s})$ & 0.217 & 0.428 & 0.631 & 0.843 & 1.088 \\
\hline
\end{tabular}


Table III. - Effects of synthetic inertia provision from a $450 \mathrm{MW}$ wind farm

\begin{tabular}{|c|c|c|c|c|c|}
\hline Kinetic energy (GWs) & 22.751 & & & & \\
\hline Non-synchronous penetration (\%) & $12.27 \%$ & & & & \\
\hline Synthetic inertia & None & & & & \\
\hline Load increase (\%) & 5 & 10 & 15 & 20 & 25 \\
\hline Frequency nadir (Hz) & 49.89 & 49.71 & 49.46 & 49.19 & 48.91 \\
\hline ROCOF (Hz/s) & 0.246 & 0.487 & 0.713 & 0.942 & 1.146 \\
\hline Synthetic inertia & Active & & & & \\
\hline Load increase (\%) & 5 & 10 & 15 & 20 & 25 \\
\hline Frequency nadir (Hz) & 49.92 & 49.8 & 49.61 & 49.36 & 49.09 \\
\hline ROCOF $(\mathrm{Hz} / \mathrm{s})$ & 0.244 & 0.47 & 0.686 & 0.906 & 1.108 \\
\hline
\end{tabular}

\section{E. Generator outage events and energy storage application}

The static and dynamic constraints are calculating with the largest single element of the power grid. In the case of the IEEE 118-bus test system, it is a synchronous generator with an apparent power of $835 \mathrm{MVA}$ and the inertia constant of 2.649 s (unit no.: 89). Table IV. summarizes the simulations of the outage events. These simulations offer the static (and if this generator is online, also the dynamic) constraint for the grid operation. The actual power of the generation in the moment of the outage is 607 MW, approximately $16,5 \%$ of the system load. The synthetic inertia activation offered around $10-15 \%$ of ROCOF reduction in the examined cases. In the case of the non-synchronous share of $25,9 \%$, only $450 \mathrm{MW}$ of wind power was equipped with the synthetic inertia capability.

Table IV. - Effects of generator outage with different level of non-synchronous generation and synthetic inertia control

\begin{tabular}{|l|c|}
\hline Remaining kinetic energy (GWs) & 21.913 \\
\hline Non-synchronous penetration (\%) & $0.00 \%$ \\
\hline Synthetic inertia & None \\
\hline Loss of generation (MW) & 607 \\
\hline Frequency nadir $(\mathrm{Hz})$ & 49.35 \\
\hline ROCOF $(\mathrm{Hz} / \mathrm{s})$ & 0.844 \\
\hline
\end{tabular}

\begin{tabular}{|l|c|c|}
\hline Remaining kinetic energy (GWs) & 20.545 & \multirow{2}{*}{} \\
\cline { 1 - 2 } Non-synchronous penetration (\%) & $12.27 \%$ & \\
\hline Synthetic inertia & None & Active \\
\hline Loss of generation (MW) & 607 & 607 \\
\hline Frequency nadir (Hz) & 49.24 & 49.44 \\
\hline ROCOF $(\mathrm{Hz} / \mathrm{s})$ & 0.963 & 0.881 \\
\hline
\end{tabular}

\begin{tabular}{|l|c|c|}
\hline Remaining kinetic energy (GWs) & 19.177 & \multirow{2}{|}{} \\
\cline { 1 - 2 } Non-synchronous penetration (\%) & $25.90 \%$ & \multicolumn{1}{|c}{} \\
\hline Synthetic inertia & None & Active \\
\hline Loss of generation (MW) & 607 & 607 \\
\hline Frequency nadir (Hz) & 49.17 & 49.4 \\
\hline ROCOF (Hz/s) & 1.108 & 0.955 \\
\hline
\end{tabular}

Energy storage systems with high ramping capability could offer synthetic inertia for power systems with higher share of non-synchronous generation. In the case of $25,9 \%$ and generator outage a $100 \mathrm{MW}$ output power storage system operated as inertial reserve with the ramping capability of 1 p.u. / $50 \mathrm{~ms}$. This grid supporting function raised the frequency nadir and limited the ROCOF significantly:

- Nadir: $49.4 \mathrm{~Hz} \rightarrow 49.5 \mathrm{~Hz}$

- ROCOF: $0.955 \mathrm{~Hz} / \mathrm{s} \rightarrow 0.645 \mathrm{~Hz} / \mathrm{s}$

Inertial response emulation with energy storage is a power type application. Therefore, it can be aggregated with other grid services or market schedules effectively. This solution is also a viable opportunity to enhance power system stability, considering the technical capabilities and economical parameters.

\section{Conclusions}

This work evaluates previously proposed inertia examination methods and operation constraints with the addition of synthetic inertia control from both nonsynchronous generators and energy storage systems to highlight the possible integration of this solution. Thus, the results are an expansion for power system stability preservation processes. There are several possible development possibilities in the methodology to provide useful information for the stability reserve planning of systems with high penetration of non-synchronous generators.

Operation constraints were examined on the IEEE 118bus system, considering the synthetic inertia provision. The studies showed that synthetic inertia is clearly visible in the system parameters during the disturbance and can help to enhance stability if utilized properly. Effects of instantaneous load increments, generator outages in different generation combinations provide useful recognitions for frequency stability evaluation as more and more data are available on the dynamic behaviour of the system. Synthetic inertia provision loosened the constraints over $10 \%$ in some cases, which highlights the practical application possibility. It is showed that energy storage systems with high ramping capability could also be used as a stability reserve, which is a new grid supporting function in systems with high share of wind and solar generation.

Utilization of renewable energy sources - especially nonsynchronous generators with highly controllable power converters - is inevitable to ensure the secure operation in the future. As the operation becomes more and more complex, advanced methods and dynamic constraints should be applied to ensure cost-effectiveness beside the reliability and security of supply. Synthetic inertia could become an integrated part of the smart grid operation and control.

\section{References}

[1] International Energy Agency, Renewables 2017: Analysis and forecasts to 2022, 2017.

[2] Mohammad Dreidy, H. Mokhlis, Saad Mekhilef, "Inertia response and frequency control techniques for renewable energy sources - a review", Renewable and Sustainable Energy Reviews Volume 69, pp. 144-155, 2017. https://doi.org/10.1016/j.rser.2016.11.170

[3] Pieter Tielens, Dirk Van Hertem, "The relevance of inertia in power systems", Renewable and Sustainable Energy Reviews 
$\begin{array}{lccl}\text { Volume } & \text { 55,Pages } & \text { 999-1009, } & 2016 . \\ \text { https://doi.org/10.1016/j.rser.2015.11.016 }\end{array}$

[4] Dimitros Zografos, Mehrdad Ghandhari, "Estimation of Power System Inertia", Institute of Electrical and Electronics Engineers Power and Energy Society General Meeting, 2016. http://ieeexplore.ieee.org/document/7741073/

[5] European Network of Transmission System Operators for Electricity (ENTSO-E): The Impact of Dispersed Generation on Continental Europe's Security of Supply, 2014. https://www.entsoe.eu/Documents/Publications/SOC/Continental _Europe/141113_Dispersed_Generation_Impact_on_Continental _Europe_Region_Security.pdf

[6] European Network of Transmission System Operators for Electricity (ENTSO-E): Requirements for Generators, 2016. https://electricity.network-codes.eu/network_codes/rfg/

[7] European Network of Transmission System Operators for Electricity (ENTSO-E): Future System Inertia (Nordic Report), 2015.

https://www.entsoe.eu/Documents/Publications/SOC/Nordic/Nor dic_report_Future_System_Inertia.pdf

[8] European Network of Transmission System Operators for Electricity (ENTSO-E): Frequency Stability Evaluation Criteria for the Synchronous Zone of Continental Europe - Requirements and impacting factors, 2016. https://www.entsoe.eu/Documents/SOC\%20documents/RGCE_S PD_frequency_stability_criteria_v10.pdf

[9] Pádraig Dally, Damian Flynn (Electricity Research Centre, University College Dublin, Ireland), Noel Cunniffe (EirGrid Plc, Dublin, Ireland), "Inertia Considerations within Unit Commitment and Economic Dispatch for Systems with High Non-Synchronous Penetrations", Institute of Electrical and Electronics Engineers PowerTech Conference, Eindhoven, 2015. http://ieeexplore.ieee.org/document/7232567/

[10] Ivonne Pena, Carlo Brancucci Martinez-Anido, BriMathias Hodge, "An Extended IEEE 118-Bus Test System with High Renewable Penetration", Institute of Electrical and Electronics Engineers Transactions on Power Systems Volume: PP, Issue: 2017. http://ieeexplore.ieee.org/document/7904729/

[11] IEEE/CIGRE Joint Task Force on Stability, "Terms and Definitions: Definition and Classification of Power System Stability", IEEE Transactions on Power Systems Volume 19 Issue $\quad 3 \quad$ pp. $1387-1401 ., \quad 2004$. https://doi.org/10.1109/TPWRS.2004.825981

[12] Peter Wall, Francisco Gonzalez-Longatt, Vladimir Terzija, "Estimation of generator inertia available during a disturbance", IEEE Power and Energy Society General Meeting, San Diego, USA 2012. https://doi.org/10.1109/PESGM.2012.6344755

[13] Xue Cao, Bruce Stephen, Ibrahim F. Abdulhadi, Campbell D. Boot, Graeme M. Burt, "Switching Markov Gaussian Models for Dynamic Power System Inertia Estimation", IEEE Transactions on Power Systems, Volume 31. Issue 5. pp. 33943403., 2016. https://doi.org/10.1109/TPWRS.2015.2501458

[14] P.M. Ashton, G.A. Taylor, A.M Carter, M.E. Bradley, W. Hung, "Application of phasor measurement units to estimate power system inertial frequency response, IEEE Power and Energy Society General Meeting, Vancouver, Canada, 2013. https://doi.org/10.1109/PESMG.2013.6672671

[15] Trent Ratzlaff: Effects Future Renewable Installations will have on System Synchronous and Synthetic Inertia (master thesis), Technical University of Delft, Netherlands, 2012., https://repository.tudelft.nl/islandora/object/uuid:1c94be1d-361940a1-86fa-4a93941cce50

[16] Johan Björnstedt: Integration of Non-Synchronous Generation (doctoral dissertation), Lund University, Sweden, 2012., $\quad$ http://www.iea.lth.se/publications/Theses/LTH-IEA1064.pdf

[17] Istvan Taczi, Istvan Vokony: "Composition of Inertial Response Emulation Mechanisms for Power System Frequency Stability Analysis", International Youth Conference on Energy,
Budapest,

Hungary,

2017.

https://doi.org/10.1109/IYCE.2017.8003733

[18] Zhiheng Zhang, Yi Wang, Heming Li, Xiaoqing Su, "Comparison of inertia control methods for DFIG-based wind turbines", IEEE ECCE Asia, Melbourne, Australia, 2013. https://doi.org/10.1109/ECCE-Asia.2013.6579222

[19] Sudipta Ghosh, Sukumar Kamalasadan, Nilanjan Senroy, Johan Enslin: Doubly Fed Induction Generator (DFIG)-Based Wind Farm Control Framework for Primary Frequency and Inertial Response Application, IEEE Transactions on Power Systems Volume 3 Issue 3, 2016., https://doi.org/10.1109/TPWRS.2015.2438861

[20] M. Marinelli, S. Massucco. Mansoldo, M. Norton: Analysis of Inertial Response and Primary Power-Frequency Control Provision by Doubly Fed Induction Generator Wind Turbines in a Small Power System, Proceedings of the 17th Power Systems Computation Conference, Stockholm, Sweden, 2011. http://orbit.dtu.dk/files/10729956/

[21] H.R. Chamorro, M. Ghandhari, R. Eriksson: Wind Power Impact on Power System Frequency Response (North American Power Symposium), 2013. https://doi.org/10.1109/NAPS.2013.6666880

[22] F. Gonzalez Longatt: Activation schemes of synthetic inertia controller on full converter wind turbine (type 4). IEEE Power \&Energy Society General Meeting, Denver, USA, 2015. https://dspace.lboro.ac.uk/dspace-

jspui/bitstream/2134/17687/1/PAPER\%20Activation\%20Sche mes\%20IEEE\%20GM\%202015.pdf

[23] Adam Stock, Bill Leithead, Shona Pennock: Providing frequency droop control using variable speed wind turbines with augmented control, EWEA Annual Conference, 2014. https://strathprints.strath.ac.uk/57188/1/Stock_etal_EWEA2014 Providing frequency droop control.pdf

[24] F. Gonzalez-Longatt, E. Chikuni, E. Rashayi: Effects of the Synthetic Inertia from Wind Power on the Total System Inertia after a Frequency Disturbance, IEEE International Conference on Industrial Technology, Cape Town, South Africa, 2013., https://doi.org/10.1109/ICIT.2013.6505779

[25] G. C. Tarnowski: Coordinated Frequency Control of Wind Turbines with High Wind Penetration (doctoral dissertation), 2012.

http://orbit.dtu.dk/files/75259610/gctarnowski_thesis1.pdf [26] F. Gonzalez- Longatt, S. M. Alhejaj, "Enabling inertial response in utility-scale battery energy storage system", IEEE Innovative Smart Grid Technologies - Asia (ISGT-Asia), pp. $605 \quad-\quad 610 ., \quad 2016 . \quad$ https://doi.org/10.1109/ISGTAsia.2016.7796453

[27] Jingya Huang, Robin Preece: HVDC Based Fast Frequency Support for Low Inertia Power Systems, 13th IET International Conference on AC and DC Power Transmission, Manchester, United Kingdom, 2017., https://doi.org/10.1049/cp.2017.0040 